\title{
LA POLÍTICA RURAL EN LA UNIÓN EUROPEA: ORÍGENES Y EVOLUCIÓN HISTÓRICA ${ }^{1}$
}

Donato Fernández Navarrete ${ }^{2}$

\section{Enmarque y significado de la política rural}

Las actuaciones de la UE en el medio rural son el resultado de la convergencia de sus dos principales políticas de gasto: la agraria y la cohesión territorial. De la primera, la política rural toma la idea de multifuncionalidad; de la segunda, la de cohesión económica y social. Pero en propiedad no se puede hablar de un modelo rural comunitario, ni tan siquiera que los programas comunitarios de actuación en el medio rural constituyan una política autónoma de la UE puesto que ésta es todavía muy tributaria de las dos fuentes que la han originado.

En sus orígenes la Política Agraria Comunitaria (PAC) apenas dejaba espacio alguno para otras actuaciones en el medio rural. Con el tiempo, las medidas de desarrollo rural, derivadas en su mayor parte de los propios cambios en la política agraria, se han ido imponiendo de forma que ya la política rural está tratando de alcanzar su mayoría de edad. El entorno rural se ha convertido, por así decirlo, en una pluriactividad que rebasa con mucho lo estrictamente agrario.

El propósito de este trabajo es el de reflexionar sobre la génesis y evolución de la política rural que ya está alcanzando cuotas de autonomía considerables y que adquirirá una dimensión aun mayor con la incorporación a la UE de nuevos Estados que todavía dedican la mayor parte de su espacio rural a la actividad agraria.

Recebido em 04/10/2004 Aceito em 15/12/2004

Catedrático de Economía Aplicada, Universidad Autónoma de Madrid. E-mail: http://www.uam.es/ donato.fernandez. 


\section{La política agraria común (PAC): primer eje de la política rural}

El primero de los ejes que está contribuyendo a la formación de la actual política rural, es el de la PAC a través de sus sucesivas reformas, en particular, desde 1992 en adelante.

En los inicios de los años sesenta, el sector agrario de los seis primeros Estados- miembros contaba con más de 14 millones de agricultores, lo que suponía una quinta parte del empleo global; sin embargo, la oferta agraria que generaban era insuficiente para atender las necesidades de la demanda ${ }^{3}$. Por ello el sector agrario comunitario fue sometido a unas reglas muy intervencionistas en el contexto de un Tratado -el de la entonces Comunidad Económica Europea- de contenido bastante liberal. La PAC ha constituído la piedra angular del proceso de integración, o al menos lo ha sido hasta la promulgación del Acta Única Europea (AUE) en que se inicia la política cohesión económica y social; y también ha sido, hasta la entrada en vigor de la unión monetaria en 1999, prácticamente la única política común que ha gestionado íntegramente las instituciones comunitarias.

Aunque la PAC es única en su concepción, desde el punto de vista financiero tradicionalmente se han contemplado dos vertientes de la misma: una, la del corto plazo, cuyo objetivo es el de hacer frente al funcionamiento cotidiano de los mercados; y otra, la del largo plazo o de estructuras, que se ha venido ocupando de financiar las reformas en el sector. Según esa filosofía, se creó, en 1962, un instrumento financiero agrario: el Fondo Europeo de Orientación y de Garantía Agraria (FEOGA) que se dividió en dos secciones: la de Garantía que tendrá por cometido financiar la política agraria a corto plazo (los gastos derivados de compras en intervención, de almacenamiento, ayudas a la producción, restituciones a las exportaciones y otros); y la de Orientación, cuya función consistiría en financiar los programas que tuviesen por objeto las reformas estructurales del sector.

Un mayor detalle sobre la PAC puede obtenerse en mi libro "Historia y Economía de la Unión Europea". Editorial Centro de Estudios Ramón Areces, Madrid, 1999. Véase en particular las págs. 322 a 331 y 341 a 343. 
Por lo que respecta a la política agraria a corto plazo, que fue la predominante durante las tres primeras décadas del proceso de integración, el modelo agrario de las Comunidades Europeas consistía en una regulación prácticamente total de la producción agraria y de su comercio con garantía de compra casi ilimitada de excedentes a cargo del FEOGAGarantía. El objetivo era atender las necesidades de los consumidores comunitarios y conseguir el mayor grado posible de autoabastecimiento en los productos alimentarios de primera necesidad. En sus orígenes, el modelo de la PAC era muy productivista sin tener muy en cuenta los costes económicos, sociales o ecológicos que pudiera originar. En ese contexto, no había hueco para una política rural que no estuviese directamente sometida a la agraria ni mucho menos que cuestionara los objetivos que fundamentaban a esta última.

La otra vertiente de la PAC, la del largo plazo o de estructuras, permaneció en esa primera etapa virtualmente congelada, tanto en sus objetivos como, principalmente, en los recursos comunitarios que le fueron asignados. Esa falta de atención comunitaria por la vertiente estructural era en parte suplida por los Estados -miembros. La Comunidad empezó a tomar conciencia de la necesidad de potenciar la política estructural cuando los principales subsectores agrarios accedieron al régimen de mercado único en los años setenta y la financiación comenzó a realizarse con recursos propios. Fue entonces cuando se intentó acometer programas que permitiesen ir reduciendo el coste financiero de la política a corto plazo. El artífice de dicha reforma fue Sicco Mansholt y fue expuesta en un Memorandum publicado por la Comisión en 1968, conocido como Plan Mansholt. Su mensaje consistía en señalar que la política de precios, por sí sola, no podía solucionar las crecientes dificultades de la agricultura comunitaria: era necesario acometer reformas técnicas, sociales y financieras en las explotaciones agrarias que permitiesen su viabilidad a largo plazo.

Las propuestas del Plan Mansholt causaron una alarma considerable entre las organizaciones agrarias y también en algunos de los Estadosmiembros, razón por la cual no llegaron a implementarse. En su lugar, 
comenzaron a ponerse en marcha una serie de acciones de carácter estructural conocidas como 'Directivas Socio-estructurales', cuyos resultados fueron muy limitados. En 1972 se promulgaron tres de estas directivas, que versaron sobre la modernización de las explotaciones, el cese en la actividad agraria y la información socioeconómica y cualificación profesional, respectivamente. La cuarta directiva, relativa a la agricultura de montaña, fue adoptada en 1975. Estas medidas, que pueden considerarse como antecedentes remotos -tanto por el tiempo como por su finalidad- de la actual política rural, toman como fuente de inspiración la misma orientación productivista que “... teñía las políticas de mercados agrarios, orientadas esencialmente a apoyar la modernización y reestructuración de explotaciones y cooperativas agrarias para garantizar el autoabastecimiento alimentario, acompañadas sólo liminarmente por programas de infraestructuras y de protección del medio ambiente" 4

Al término de la vigencia de las cuatro directivas antes citadas, que tuvo lugar a mediados de los años ochenta, se refundieron y actualizaron por el Reglamento 797/85 del Consejo de 12 de marzo de dicho año,en un solo programa denominado "Mejora de la eficacia de las estructuras agrarias”. En 1987 este Reglamento fue parcialmente modificado para dar entrada a una nueva modalidad de política estructural: la de extensificación de la producción ${ }^{5}$. La finalidad de la extensificación era la de contribuir al equilibrio entre oferta y demanda agraria y con dicho propósito se preveía el establecimiento de un régimen de ayudas para estimular la reconversión en productos no excedentarios y la extensificación de los excedentarios ${ }^{6}$.

Con la reforma de los fondos estructurales de 1988, la vertiente estructural de la PAC pasó a insertarse en un contexto de política regional (de

\footnotetext{
4 Massot Marti, A. "Las medidas de desarrollo rural de la Unión Europea: las reformas de la PAC y de la política de cohesión". Diciembre de 2003. La versión que se cita es la del documento que amablemente me ha proporcionado directamente por el propio autor.

Reglamento 1760/87 del Consejo de 15 de junio. DOCE-L 167, de 26 de junio.

6 En dicho Reglamento se entiende por extensificación la disminución de al menos un $20 \%$ de la producción del bien en cuestión, sin que por ello se vean incrementadas las capacidades de otros productos que sean excedentarios. Comenzó a aplicarse en cereales, carne de vacuno y vino.
} 
desarrollo del medio rural) incrementando de manera destacada su financiación. No fue éste el único cambio; la propia PAC resultó profundamente modificada en 1992 por una reforma que le dio prácticamente la vuelta a la filosofía que la había inspirado en los años sesenta. Efectivamente, la PAC pasó de proteger y garantizar la demanda (la compra de excedentes) a focalizar su atención en el control de la oferta. Su objetivo, por tanto, ya no iba a consistir en lograr el mayor grado de autoabastecimiento sino en luchar contra los excedentes y en liberalizar progresivamente la PAC.

La reforma de la PAC de 1992 ha recibido nuevos impulsos liberalizadores en 1999 y 2003 . Es obvio que desde el punto de vista de las necesidades alimenticias comunitarias, el contexto de la reforma de la PAC de 1992 y de los retoques posteriores no era el mismo que el de su creación en los inicios de los sesenta. Actualmente el problema agrario comunitario no radica en hacer frente a la escasez de alimentos, como lo era entonces, sino en resolver los amplios desajustes que ha ido originando la vieja PAC, entre los que se encuentran los desfases entre oferta y demanda interna, la dificultad para financiar excedentes, el beneficio desmedido en favor de las grandes explotaciones y, muy particularmente, las críticas que venía recibiendo el proteccionismo que la PAC dispensaba a las importaciones agrarias y las fuertes subvenciones a las exportaciones ${ }^{7}$.

En tales condiciones, la reforma de la PAC 1992 -conocida como la reforma Mac Sharry, nombre del Comisario de Agricultura que la llevó a cabo-, se hacía imprescindible. Tras una serie de medidas preliminares que se venían acometiendo desde mediados de los ochenta, la verdadera reforma de la PAC se acomete en mayo de 1992 con el propósito de desbloquear las negociaciones de la Ronda Uruguay del GATT que, por primera vez, iba a incluir al comercio agrario entre sus competencias. Es a partir de esta fecha cuando comienza a revisarse seriamente los mecanismos de la PAC y más en concreto los reglamentos de las Organizaciones Comunes de Mercado (OCM) con el fin de acomodarlas

García Azcárate, T. "Hacia una nueva legitimidad para la política agraria común”. Palau, Revista Valenciana de Hacienda Pública, número correspondiente a mayo-agosto de 1991. 
a la nueva situación ${ }^{8}$. Como resultado de dicha reforma, en 1992 surge una nueva PAC que somete a una revisión profunda el modelo que fue instaurado en $1962^{9}$. Sentadas estas bases, todas las reformas posteriores -más precisamente revisiones- de la PAC han ido en la misma línea: liberalizar los precios con el objeto de hacer más compatible el comercio agrario comunitario con las normas de la OMC.

A diferencia del pasado, en el nuevo modelo que se inicia en 1992 se introducen programas de regulación de oferta, del mismo modo que ya se había hecho en los Estados Unidos en la década de los treinta. Las principales novedades de la reforma de la PAC de 1992, fueron las dos siguientes: en primer lugar, se disminuyó la regulación del sector agrario principalmente reduciendo los precios institucionales y sustituyendo el apoyo ofrecido a los precios con garantía de compra por otro que ponía su acento en las ayudas directas a las rentas; y en segundo lugar, se introdujeron una serie de programas complementarios denominados 'medidas de acompañamiento', que a lo largo de los años han ido adquiriendo una importancia capital en la definición de la política rural. Las medidas de acompañamiento no sólo tenían el propósito de contribuir a aliviar las cargas financieras de la sección Garantía del FEOGA, sino también de enmarcar la política agraria en un contexto de desarrollo rural en el que los aspectos ecológicos, entre otros, pasaron a tener una dimensión singular.

Las medidas de acompañamiento de la reforma de la PAC de 1992, que aun están en vigor, fueron las tres siguientes:

- Programas medioambientales. Tales programas tienen una doble finalidad: limitar la producción agraria potenciando la extensificación de los productos (reducir los rendimientos) y proteger el espacio rural. Estos programas cubren una serie de medidas, tales como agricultura ecológica,

\footnotetext{
La primera fase de la reforma afectó a los cultivos herbáceos -cereales, oleaginosas y proteaginosas-, al tabaco, ganado vacuno y ovino y los productos lácteos. Se dejó para más adelante la revisión de otras OCM , tales como la del arroz, azúcar, aceite de oliva y de frutas y hortalizas que han ido acometiéndose en los años posteriores.

9 Véase al respecto García Azcárate, T. en "Reflexiones sobre el Libro Verde y la crisis de la Política Agraria Común”. Revista de Estudios Agrosociales, $n^{\circ} 136$ (julio-septiembre), 1986. Y también del mismo autor "Modernización agraria y reforma de la PAC". Papeles de Economía Española, nº 60-61, 1994.
} 
conservación de razas autóctonas, agricultura extensiva, etc. Naturalmente en este contexto se inscribe también la mejora en la calidad de los alimentos que cada vez en mayor medida demanda el consumidor.

- Indemnizaciones por jubilación anticipada a los agricultores a partir de 55 años que deseen ceder sus tierras a agricultores más jóvenes o bien para destinarlas a usos forestales y de conservación ${ }^{10}$.

- Ayudas a la forestación y conservación de las tierras de labor arbitrando primas anuales que compensen las disminuciones de rentas ${ }^{11}$.

A estos tres componentes de la reforma de 1992 se añadieron, en la reforma de 1999, otras dos: el régimen aplicable a las zonas desfavorecidas (principalmente zonas de montaña y cuya reglamentación originaria se remontaba a la directiva socioestructural de 1975) y áreas con restricciones ambientales cuyo objetivo básico es el de conservar en determinadas zonas - mediante la subvención de rentas- una comunidad rural que permita mantener el entorno ambiental y fomentar sistemas agrarios sostenibles ${ }^{12}$.

Las medidas de acompañamiento de la reforma de la PAC de 1992 pueden tomarse como el punto de partida de la política rural comunitaria, enfocada ésta desde un punto de vista sectorial. Con ellas se intenta compatibilizar los métodos de producción y el respecto al medio ambiente para alcanzar una sostenibilidad mutua. La protección del medio ambiente, por tanto, pasa a constituir uno de los objetivos de la nueva PAC. Y desde el punto de vista financiero, dichas acciones de carácter estructural pasaron a ser financiadas por la sección Garantía del FEOGA y no a través de la de Orientación, como parece hubiera sido lo lógico ${ }^{13}$.

10 Reglamento (CEE) 2079/92, DOCE- L de 30 de julio de 1992

11 Reglamento (CEE) 2080/92, DOCE-L de 30 de julio de 1992.

12 Ambos programas se contienen en el Reglamento (CE) 1257/1999 del Consejo publicado en el DOCE de 26 de junio de 1999.

13 Esta fórmula de financiación continúa todavía vigente. En las perspectivas financieras de la Agenda 2000, dice que con la excepción de las regiones incluidas en el Objetivo 1 (las menos desarrolladas), que son financiadas por el FEOGA-Orientación, las medidas de política rural se financiarán exclusivamente por la sección de Garantía del FEOGA. Y así parece que continuará en un futuro. 
Las medidas de acompañamiento contenidas en la reforma de la PAC de 1992 -complementadas con las de 1999, no fueron un elemento marginal de la misma. Al contrario, adquieren una importancia central de la reforma, por cuanto el sector agrario pasa a inscribirse en una nueva dimensión que ya no se limita, como en el pasado, a proporcionar alimentos abundantes y baratos para el consumidor, sino en producir alimentos de mayor calidad y ofrecer una serie de servicios que presten especial atención al cuidado del entorno y eviten su degradación progresiva, como, por ejemplo, el turismo rural. En definitiva, estas medidas de acompañamiento atribuyen al medio rural una dimensión ecológica y de desarrollo sostenible que cada vez adquiere mayor relieve y que están en el origen comunitario de lo que hoy se conoce como la función de multifuncionalidad del sector agrario.

En conclusión, la reforma de 1992 introdujo mecanismos de flexibilización ágiles que permitían adecuar la PAC a un nuevo tipo de agricultura en la que la gran explotación era la principal destinataria de la nueva política de mercados. Como escribe Regidor, en el sector agrario comunitario comienza a diferenciarse entre agricultura comercial y territorial. La primera corresponde a las explotaciones viables económicamente y se asocia, por lo común, a explotaciones de gran dimensión modernizadas y convenientemente gestionadas que producen para el mercado (las que tienen un margen bruto anual de 18.000 o más UDEs -Unidad de Dimensión Económica-). La segunda, la forman pequeñas y medianas explotaciones de tipo familiar que carecen de viabilidad económica y cuya principal misión es la preservación del paisaje y de los recursos naturales y que para sobrevivir tiene que estar fuertemente subvencionada ${ }^{14}$.

Adicionalmente, dada la resistencia de los Estados- miembros a incrementar los recursos del presupuesto común, se ha iniciado una progresiva renacionalización de la PAC, cuya consolidación se produce

\footnotetext{
${ }^{14}$ De las 1.023 mil explotaciones familiares existentes en España en 1997, sólo 117 mil eran viables económicamente y 916 mil no lo eran. Si a esas 117 mil les sumamos otras 38 mil explotaciones viables de carácter no familiar, tenemos completo el panorama de la explotación agraria española. Regidor, J.R. "El futuro del medio rural en España. Agricultura y desarrollo económico". Consejo Económico y Social, Madrid, 2000, págs. 97 a 112.)
} 
de forma definitiva en la Constitución europea y en el proyecto de perspectivas financieras de la Comisión para el periodo 2007-13. Por otro lado, también es destacable el impulso financiero que comenzaron a recibir los programas de desarrollo rural, aproximándose al 12\% de los gastos previstos para la 'Directriz agrícola' durante el periodo cubierto por la Agenda 2000 (2000-06).

El Consejo de Ministros de agricultura, en su sesión del 11 de marzo de 1999, aprobó junto con los precios comunes que cubren el marco temporal de la Agenda 2000, un nuevo paquete de medidas liberalizadoras de la PAC. Esta nueva revisión de la PAC, siguiendo la línea ya marcada por la reforma de 1992, obedece, principalmente, a la ampliación de la UE hacia el Este que implica incrementos considerables en el potencial agrario comunitario y que contribuirá a agravar los problemas de financiación de la $\mathrm{PAC}^{15}$. En compensación, se refuerza la política rural que, entre otras ventajas, es más barata de mantener. De hecho, en la citada reforma la política rural pasa a convertirse en el denominado segundo pilar de la $P A C$, que es el que le da a la actividad agraria esa visión de multifuncionalidad a la que hemos hecho referencia. En el Considerando primero del Reglamento 1257/99 -así como en el apartado 2 del artículo 1 - se establece “... que es preciso que una política común de desarrollo rural acompañe y sirva de complemento a otros instrumentos de la política agrícola común y contribuya así a la consecución de los objetivos de esa política, establecidos en el apartado 1 del artículo 33 del Tratado"16.

La PAC nuevamente se somete a revisión en septiembre de 2003. Se prosigue en la liberalización de la misma y se introduce un mecanismo de modulación financiera obligatoria que pretende abaratar de manera importante los costes de directos de aquella. En esta reforma, el segundo

\footnotetext{
La ampliación hacia el Este supone incrementar las actuales tierras agrícolas en un 50\% y doblar el número de ocupados en el sector. La Comisión señala que es inviable aplicar a tales países los actuales precios de sostenimiento y de pagos directos que realiza la PAC puesto que ello originaría considerables distorsiones de rentas en las áreas rurales y se incrementarían los ya importantes excedentes que existen en azúcar, productos lácteos y carnes.

16 Reglamento (CE) 1257/1999 del Consejo de 17 de mayo de 1999. Este Reglamento es el más importante que existe hasta el momento sobre desarrollo rural.
} 
pilar de la PAC -la política rural- lejos de adquirir mayor autonomía como cabía esperar, se vincula aún más al primer pilar -a la política de mercados-, haciendo patente su dependencia de aquella. Además, con el objeto de lograr un mayor equilibrio entre los instrumentos destinados a promover una agricultura sostenible y los destinados a fomentar el desarrollo rural, se introduce un sistema de modulación financiera consistente en reducir progresivamente los pagos directos obligatorios durante el periodo 2005-2012. De esta forma, a partir de un cierto importe, todos los pagos directos que haya de percibir un agricultor comunitario se reducirán cada año en los siguientes porcentajes: en un $3 \%$ en el año 2005 , 4\% en 2006 y en un 5\% desde el año 2007 a 2012. El ahorro realizado con tales reducciones se destinará, una vez deducidos ciertos importes, “... a sufragar medidas incluidas en la programación de desarrollo rural y financiadas por la Sección de Garantía del FEOGA, de conformidad con el Reglamento (CE) no 1257/1999"17.

En definitiva, el principal aporte que realiza la PAC a la política rural es sin duda alguna, el concepto de multifuncionalidad de la actividad agraria. Su primera manifestación fueron las medidas de acompañamiento de la reforma de la PAC de 1992. La multifuncionalidad del sector agrario se manifiesta, al menos, en las siguientes cuatro dimensiones: la económica, la social, la seguridad alimentaria y la ambiental ${ }^{18}$.

La económica es la función primaria, directa e inmediata de dicho sector: la de producir alimentos; y que es la que generalmente se ha tenido en cuenta al valorar este sector. Las otras tres funciones trascienden propiamente a la dimensión económica: en ellas se recogen lo que podríamos denominar los elementos no comercializables del sector agrario; entre tales elementos están los sociales (tales como el ocio), los medioambientales (mantener un entorno limpio) y la seguridad alimentaria (en términos de calidad y de control estratégico).

\footnotetext{
${ }^{17}$ Véase art. 10 del Reglamento (CE) 1782/2003 del Consejo de 29 de septiembre de 2003.

${ }^{18}$ Esta clasificación la he tomado de la Tesis Doctoral de Antonio Ciriaco Cruz "La multifuncionalidad o roles de la agricultura en el desarrollo: opciones regionales". Universidad Autónoma de Madrid, julio de 2004, págs. 207-278.
} 
La parte no comercializable del sector agrario genera una serie de servicios que son proporcionados por el sector agrario a la sociedad; es decir, son externalidades positivas, que nadie remunera pero que, al ser públicas, requieren de protección económica especial si se pretende que el sector agrario siga cumpliendo con tales funciones. De alguna forma, al crearse la OMC en 1994 e incluir al comercio agrario entre sus ámbitos de actuación, se también se contemplaron estos aspectos agrarios que no son objeto de comercio o que no afectan al mismo de manera directa; por tales razones pueden recibir ayudas públicas por parte de los Estados sin que por ello se vulnere las normas sobre comercio agrario de la OMC (tales ayudas están contenidas en la llamada Caja Verde de la OMC). La cuestión reside en la extensión de lo que se entienda por aspectos agrarios no comercializables pues mientras algunos Estados u organizaciones entre ellas la UE- consideran que son parte de la multifuncionalidad agraria no comerciable y por lo tanto objeto de ayudas públicas, otros (entre ellos de manera destacada los Estados Unidos) consideran tales ayudas como una protección encubierta del comercio agrario.

\section{La política de cohesión económica y social: segundo eje de la política rural}

La política de cohesión económica y social fue introducida por el AUE de 1987, aunque fue notablemente reforzada por el Tratado de la Unión Europea (TUE) de Maastricht que entró en vigor en noviembre de 1993. Dicha política tiene por finalidad promover un desarrollo armonioso de los Estados-miembros de la UE. Para alcanzar la mencionada cohesión, se requiere el concurso de importantes recursos públicos con el objeto de reducir las diferencias de renta y de riqueza entre las regiones comunitarias - a través de los fondos con finalidad estructural- y entre los Estados-miembros -objetivo del nuevo fondo de Cohesión creado por el TUE-. El instrumento básico es el presupuesto comunitario que desde 1988 en adelante incrementó de manera muy notable los recursos destinados a la política estructural en los llamados paquetes financieros Delors I, Delors II y Agenda 2000. 
Así pues, el objetivo específico que el AUE atribuye a la cohesión económica y social es el de reducir las diferencias de renta percápita entre las regiones, incluidas entre ellas las zonas rurales. La reforma de los fondos estructurales se produjo en 1988 y su base residió en la concentración de los esfuerzos financieros en las regiones más desfavorecidas ${ }^{19}$. Lo que se pretendía con dicha reforma era darle a la política estructural un carácter coordinado mediante la actuación conjunta de uno o más fondos estructurales con el objeto de que el impacto de las inversiones fuese mayor. A partir de entonces, las actuaciones se han centrado, principalmente, sobre la modernización de las infraestructuras del transporte con el fin de disminuir el aislamiento tradicional de tales regiones de los ejes de mayor desarrollo; la potenciación de los sectores productivos, sobre todo de la agricultura y de la pesca; y un mejor aprovechamiento de los recursos humanos mediante programas de formación y de reciclaje profesional ${ }^{20}$.

Los programas que se desarrollan en las actuaciones estructurales se ajustan a una serie de Objetivos. Entre 1988 y 1999 -Perspectivas financieras Delors I y II- se definieron seis grandes Objetivos (el sexto fue introducido en 1995 con ocasión de la ampliación comunitaria a tres nuevos miembros). De ellos, el primero y el sexto fueron previstos para las regiones más atrasadas; el segundo para las áreas industriales en declive; el quinto para el sector agrario -en su doble vertiente de reconversión agraria, apartado (a), y zonas rurales, apartado (b)-, mientras que los Objetivos tercero y cuarto se previeron para atender el paro y la recualificación profesional en las zonas de reconversión industrial.

\footnotetext{
A tal efecto se procedió a dictar el Reglamento Marco 2052/88 CEE para cuya aplicación se actualizaron los Reglamentos de cada uno de los fondos (FEDER, FEOGA-Orientación y FSE).

${ }^{20}$ Los programas son cofinanciados por la Comunidad y los Estados- miembros, aunque en proporciones diferentes según los objetivos concretos que se persigan. Los proyectos que deseen obtener una subvención comunitaria deben inscribirse en los programas establecidos por los Estados- miembros, puesto que las inversiones han de hacerse con arreglo a una programación. Dicha programación consiste en la presentación por los Estadosmiembros de un plan para cada objetivo o para cada región en el que se efectúe un diagnóstico socioeconómico y se propongan estrategias y objetivos. Posteriormente se acuerda el marco de apoyo comunitario (MAC) entre las autoridades nacionales, regionales y la Comisión, siendo ésta última quien lo aprueba mediante una decisión formal. Este esquema de programación en tres fases experimentó modificaciones para el periodo 199499 consistentes en refundir las citadas tres fases en un Documento único de programación (DOCUP) con el fin de simplificar la tramitación de las ayudas. Para el periodo 2000-2006, se utiliza obligatoriamente el DOCUP en los Objetivos 2 y 3 , pudiéndose utilizar también para el Objetivo 1 si la asignación comunitaria no rebasa el millón de euros.
} 
Desde la óptica regional, las perspectivas financieras Delors I pueden tomarse como el inicio de la política rural comunitaria. Efectivamente, aunque con actuaciones dispersas, programas de carácter local aparecen en el Objetivo 1 (regiones más atrasadas en las que actúan conjuntamente todos los fondos) y de forma más explícita en el Objetivo $5 b^{21}$. El punto de inflexión que marca el comienzo de una política rural autónoma es el año 1988, fecha en que la Comisión hace pública una Comunicación titulada" El futuro del mundo rural", que supone el soporte teórico de una política rural más dependiente de la política regional que de la agraria. ${ }^{22}$.

La Agenda 2000, que cubre el periodo financiero 2000-2006, procede a una remodelación profunda de los anteriores objetivos, reduciéndolos de seis a tres con el objeto de incrementar la eficacia de los fondos y simplificar su complicada gestión administrativa. Las principales aportaciones referidas a la política rural son la de considerarla como segundo pilar de la PAC y tratar de perfilar algo más su ámbito de actuación mediante el Reglamento 1257/1999.

En la propuesta de Perspectivas financieras de la Comisión para el periodo 2007-13, la política de cohesión pasará a convertirse en la primera de las políticas de gasto de la Unión. Por primera vez en la historia de la UE, los créditos de compromiso previstos para la cohesión desplazarán a los agrarios, política esta última que sigue su proceso imparable de liberalización e incluso de renacionalización.

Además de los programas anteriores clasificados por Objetivos, la Comisión ha establecido otros que reciben el nombre de Iniciativas comunitarias. Las Iniciativas comunitarias son programas específicos realizados por la Comisión para atender determinadas prioridades como,

\footnotetext{
21 Recordemos que el Objetivo 5, que contemplaba actuaciones en política agraria en zonas desarrolladas, se desdoblaba en dos: el Objetivo 5-a que quedaba reservado para la política agraria estructural (ámbito del FEOGA-Orientación) y el Obejtivo 5-b en el que encajaban las zonas rurales y en cuya financiación participaba además del FEOGA-Orientación, el FEDER y el FSE.

22 Comisión de las Comunidades Europeas "El futuro del Mundo Rural". Comunicación de la Comisión de las Comunidades Europeas al Parlamento Europeo y al Consejo. COM (88) 5012 Final.
} 
por ejemplo, el fomento de igualdad de oportunidades entre las mujeres y los hombres en la formación profesional, o el desarrollo de zonas rurales. Durante el periodo 1994-99, la Comunidad puso en marcha un buen número de tales Iniciativas -hasta un total de 13- que la Agenda 2000 redujo a 4 para el periodo 2000-06. En el marco de las próximas perspectivas financieras (2007-2013), las Iniciativas comunitarias pasarán a integrarse en un nuevo programa que probablemente se denomine de Cooperación territorial. Dicha Cooperación tendrá por objeto conseguir un desarrollo armonioso y equilibrado entre regiones transfronterizas y transnacionales de la UE mediante el impulso de programas conjuntos para hacer frente a los problemas urbanos y rurales específicos de cada región.

Entre las distintas Iniciativas comunitarias en vigor que más directamente se relacionan con el medio rural, ha de desatacarse la relativa al 'Programa $L E A D E R$ '. Este programa supone un apoyo a las actividades de desarrollo rural mediante un aprovechamiento al máximo de los recursos que ofrece la localidad en cuestión. El programa está sujeto a disposiciones particulares que le permite incidir -reforzando la actuación de los fondos estructurales- en determinadas zonas rurales para impulsar su desarrollo. El Programa LEADER se puso en marcha en 1991- LEADER-I y tuvo su continuación en el periodo entre 1994 y 1999 con el LEADER II; para el periodo 2000-06 recibe el nombre de LEADER Plus En ellos se puede observar una cierta evolución: el LEADER I tuvo un marcado enfoque territorial integrado, el LEADER II exigía que los proyectos contasen con un cierto carácter innovador y el LEADER Plus abre su aplicación a todos los territorios rurales y se produce un reforzamiento en las formas participativas de organización y de cooperación entre los territorios rurales. El principal interés del Programa LEADER reside en poner en tensión las fuerzas locales para que surjan iniciativas de desarrollo endógeno. Mediante este programa, la Unión Europea ha dado paso a una iniciativa de desarrollo rural de ámbito comarcal que está dando buenos resultados.

Los requisitos exigidos por la Comisión para la aprobación de un LEADER son muy estrictos. El ámbito territorial ha de ser geográficamente reducido y homogéneo, si bien no ha de coincidir necesariamente con las divisiones 
administrativas de las regiones NUTS II y III; en el ámbito económico y social, el colectivo poblacional debe situarse entre 10.000 y 100.000 habitantes, y no sobrepasar la densidad máxima de 120 habitantes/km2; el plan de desarrollo a realizar debe contar con una masa de recursos humanos, económicos y financieros suficiente, a la vez que se exige que la estrategia de desarrollo sea viable, integrada y sostenible. El programa LEADER, en definitiva, pretende revitalizar el desarrollo económico endógeno de las comarcas en las que se implante, puesto que son las fuerzas locales las que han de tomar la iniciativa al igual que las que gestionan y fijan las prioridades del proyecto de desarrollo. Este programa también permite crear redes nacionales y comunitarias de desarrollo rural que posibilitem el intercambio de información entre las diversas comarcas rurales.

No obstante, la Comisión, consciente de la dificultad de cumplir con las exigencias del programa LEADER en un buen número de comarcas rurales, adoptó la Decisión de 18 de junio de 1996 por la que se creaba el Programa de Desarrollo y Diversificación Económica de Zonas Rurales (PRODER), de aplicación en zonas pertenecientes a regiones del Objetivo 1. La finalidad que persigue un PRODER es muy similar a la de un LEADER: impulsar el desarrollo endógeno de las zonas rurales de las mencionadas regiones del Objetivo 1, promocionando iniciativas que contribuyan a incrementar el nivel de vida de sus habitantes. El PRODER puede considerarse como el hermano pobre del LEADER, puesto que se aplica en aquellas regiones en las que un programa LEADER tiene escasas o nulas posibilidades de ser aprobado por la Comisión. Queda excluida la posibilidad de coexistencia de ambos programas sobre una misma zona rural ${ }^{23}$.

En conclusión, actuaciones de política rural desde la perspectiva espacial encontramos en todas las perspectivas financieras desde que éstas se

\footnotetext{
${ }^{23}$ Algunas de las diferencias más señaladas entre ambos programas pueden sintetizarse en las siguientes: el LEADER es una iniciativa comunitaria que se añade y refuerza la financiación de los fondos estructurales, el PRODER no; el LEADER teóricamente puede operar en cualquier área rural (ya sean Objetivo 1 ó 2), el PRODER sólo en las de las regiones del Objetivo 1; el LEADER exige una homogeneidad territorial, económica y social y un dinamismo económico que no requiere el PRODER.
} 
pusieran en marcha en 1988, tanto formando parte de los Objetivos de programación como de las Iniciativas de la Comisión y particularmente en el Leader.

\section{Hacia una política rural autónoma}

Sentadas las bases de la doble procedencia de la política rural, plasmada en los epígrafes precedentes, resta por considerar el grado de autonomía de la que goza dicha política. Para aproximar a esta cuestión, deben tenerse en cuenta, bajo mi punto de vista, tres cuestiones: en primer lugar, definir lo que debe entenderse por medio rural; en segundo lugar, determinar a qué instancias políticas corresponde definir, ejecutar y financiar las medidas de política rural; y en tercer lugar y último delimitar el conjunto de medidas y programas que se aplican al medio rural.

Comenzando por el primero de los aspectos citados, la delimitación física y humana- de lo que debe entenderse como ámbito rural es una cuestión que no resulta fácil. Generalmente se define lo rural como el espacio en el cual los asentamientos o núcleos de población no superan los 10.000 habitantes y cuya principal actividad productiva es la agraria. Esta definición resulta objetable por una serie de razones. En primer lugar, lo 'agrario' no supone automáticamente un paralelismo con lo 'rural', cuestión ésta que se retomará más adelante. En segundo lugar, el dato poblacional tampoco es determinante en la consideración de una zona como 'rural', puesto que depende mucho de las características demográficas y económicas del área. De esta forma, se puede observar que es frecuente la existencia de núcleos de población que no alcanzan los 10.000 habitantes, pero que por la orientación de sus actividades productivas y por los patrones de comportamiento de sus habitantes, se consideran zonas urbanas (por ser dependientes, en la mayoría de los casos, de un núcleo matriz); por otra parte, también pueden encontrarse casos de zonas rurales en núcleos de población de UE que superan los 10.000 habitantes . 
En la Unión Europea se utiliza como criterio de delimitación la densidad de población. Según este criterio, se consideran comunidades rurales los espacios cuya densidad de población no supera los 100 habitantes por km2; de su aplicación para el año 2000, más del $81 \%$ de la superficie comunitaria (de la UE de los 15) era rural y en ella residía más del $17 \%$ de su población ( $24 \%$ en el caso de España). La aplicación estricta de este criterio lleva a considerar, por ejemplo, que el 50,6\% de la población de Finlandia y el $66,8 \%$ de la de Suecia vive en comunidades rurales. Tomando como base la densidad de población, la UE distingue entre espacios predominantemente rurales (cuando más del $50 \%$ de la población habita en comunidades rurales), significativamente rurales (cuando habita en comunidades rurales entre el 15 y $50 \%$ de la población) y predominantemente urbanizada (menos del $15 \%$ de la población vive en comunidades rurales); según esta tipología, los porcentajes de población de la UE-15 que viven en cada uno de los mencionados ámbitos, son los siguientes: 9,7\% (predominantemente rural), 29,8 (significativamente rural) y 60,5 (predominantemente urbana) ${ }^{24}$; aplicado a Luxemburgo, que es el país con máxima renta percápita de toda la UE, toda su población habitaría en una zona significativamente rural.

Teniendo en cuenta lo confuso del concepto de área rural, es preciso que se perfile con mayor precisión. En el supuesto de España, parece bastante adecuado el criterio adoptado por la Encuesta Sociodemográfica realizada por el Instituto Nacional de Estadística a finales de 1991, que cataloga como 'área rural' a los núcleos de población de hasta 10.000 habitantes ,situados a 15 o más kms de ciudades de más de 400.000 habitantes y a $25 \mathrm{Kms}$ si dichas ciudades superaban el millón (casos de Barcelona y de Madrid).

La segunda de las cuestiones que debe clarificarse es la competencial; es decir, quién tiene el poder para diseñar y ejecutar la política rural.

\footnotetext{
24 Ministerio de Agricultura, Pesca y Alimentación (MAPA). "Hechos y cifras del sector agroalimentario español 2000”. Madrid, septiembre de 2000, pág. 17.
} 
Desde este punto de vista, la política rural es una competencia compartida y cofinanciada entre la Unión y los Estados-miembros y por ello está sometida al principio de subsidiariedad. Según la normativa comunitaria, las competencias compartidas concurrentes -en contraposición con las 'complementarias' - únicamente podrán ser ejercidas por los Estados en la medida que no lo haga la Unión. Esto equivale a decir que en el futuro la política rural se comportará de hecho como si fuese una competencia en exclusiva de la Unión.

Finalmente, la tercera de las cuestiones que debe clarificarse es el alcance de la política rural, o lo que es lo mismo, su ámbito de actuación. Para acotar dicho ámbito hemos de acudir al Reglamento 1257/1999 que es el que contiene el paquete de medidas de política rural, objeto de financiación comunitaria que está actualmente en vigor. ${ }^{25}$. Tales medidas se consideran como un paquete por estar contenidas en una misma disposición; no obstante, más que una política de desarrollo rural de carácter integral, cabe hablar de un conjunto de programas de desarrollo agrario (en el contexto de las reformas de la PAC) y, en sentido estricto, sólo uno de los programas es de desarrollo regional. Los programas que contempla el referido Reglamento 1257/1999 son los siguientes:

- Inversiones en explotaciones agrarias, con objeto de aumentar la renta agraria y mejorar las condiciones de vida, trabajo y producción (arts. 4 a 7).

- Instalación de jóvenes agricultores: que tengan menos de 40 años, que posean capacidad y competencia profesional, que se establezcan por primera vez como titulares de explotación y que cumplan las normas mínimas en materia de medio ambiente (art. 8).

- Ayuda a la formación para aumentar la capacidad y competencia profesional de los agricultores (art.9).

${ }^{25}$ Dicho Reglamento ha sido modificado por el Reglamento (CE) 1783/2003 del Consejo de 29 de septiembre de 2003. La financiación de la política rural se realiza principalmente a cargo del FEOGA (secciones de Garantía y de Orientación) y se enmarca en las perspectivas financieras de la Agenda 2000. 
- Cese anticipado en la actividad agraria: fomentar la sustitución de agricultores mayores por jóvenes, dedicar tierras agrarias a usos no agrarios, etc. Tener al menos de 55 años, haber ejercido la actividad los 10 años anteriores y abandonarla definitivamente. Regula también condiciones de cesionario y trabajador agrario (arts. 10 a 12).

- Zonas desfavorecidas y con limitaciones medioambientales específicas - Definición y características de tales zonas y regímenes de ayudas previstos (arts. 13 a 21).

- Medidas agroambientales. Ayudas para el uso de métodos de producción que protejan el medio ambiente: protección y mejora medio, extensificación producción, conservación entorno agrario, etc. (arts. 22 a 24).

- Transformación y comercialización de productos agrarios (arts. 25 a 28).

- Silvicultura. Ayudas para el mantenimiento y desarrollo de los bosques: gestión forestal, mejora de recursos y aumento de superficies forestales (arts. 29 a 32).

- Adaptación y desarrollo de zonas rurales: ayudas para la mejora de tierras, reparcelación, protección y conservación del patrimonio rural, recursos hídricos, turismo, artesanía local, etc. (art.33).

Como puede apreciarse, nueve de los diez programas antes citados, que figuran como de desarrollo rural, están relacionados con el desarrollo agrario y sólo uno con el regional: el de adaptación y desarrollo de zonas rurales.

Desde el punto de vista de la financiación comunitaria del medio rural, cabe distinguir dos grandes grupos. El primero de ellos está formado por los programas que forman parte de las medidas de acompañamiento de la PAC (como son las agroambientales, jubilación anticipada, forestación, zonas desfavorecidas y zonas con limitaciones ambientales) cuya 
financiación corre a cargo del FEOGA-Garantía ${ }^{26}$. El segundo grupo lo componen las restantes medidas de desarrollo rural contenidas en el Reglamento 1257/1999 antes citado y que se financian al amparo de los fondos estructurales bien bajo la programación de las regiones del Objetivo 1 (cuando las zonas rurales se sitúen en regiones menos desarrolladas), o bien de las regiones del Objetivo 2 (cuando las zonas rurales se sitúen en regiones en reconversión). En las regiones Objetivo-1 el instrumento financiero por excelencia de los programas rurales es el FEOGAOrientación y para ciertas líneas, FEDER; y en el caso de las regiones Objetivo 2, el FEOGA-Garantía y para ciertas líneas, el FEDER ${ }^{27}$.

Adicionalmente a las actuaciones financieras anteriores en zonas rurales, también existe, como ya hemos visto anteriormente, otra actuación especial que es el programa LEADER que lo hace en el ámbito de la Iniciativas comunitarias dependientes de la Comisión y cuya financiación corre a cargo del FEOGA-Orientación, tanto en las regiones Objetivo 1 como en las de Objetivo $2^{28}$.

Por lo tanto, la política rural, además de estar falta de autonomía, también lo está de clarificación. Como hemos visto, existen actuaciones de diverso tipo y en su financiación confluyen uno o más fondos estructurales diferentes según los programas de que se trate sin que exista una razón aparente que lo justifique plenamente. El panorama actual es, pues, bastante confuso. Consciente de este problema, la Comisión se propone clarificar y simplificar las actuaciones en el medio rural para las próximas perspectivas financieras 2007-13. El 15 de julio de 2004 hizo pública su propuesta sobre el desarrollo rural para el referido periodo, cuyas principales características generales pueden resumirse en las tres siguientes:

26 Desde este punto de vista el FEOGA-Garantía puede considerarse también como un fondo estructural.

27 En ambos supuestos el Reglamento base por el que se rigen es por 1260/1999 y, subsidiariamente, por el Reglamento 1257/1999 de ayudas al Desarrollo Rural.

28 La dotación financiera del LEADER Plus para el periodo 2000-06 es 2.020 millones de euros. Puede subvencionar hasta 
- Reforzamiento financiero de la política rural y simplificación de su actuación. Dicho reforzamiento es obvio si tenemos presente que por parte comunitaria de los poco más de 4.000 millones de euros (de 1999) anuales, previstos por la Agenda 2000, se pasará a 13.700 millones euros de 2006 en el paquete Prodi (2007-13). Al ser programas cofinanciados, la participación comunitaria como norma general no superará el 50\% de la inversión -excepto en las regiones de la convergencia que según los objetivos que se especifican más abajo, podrá llegar hasta el 75 u 80\%correspondiendo la otra mitad al Estado nacional en el que se aplique el programa

- Se crea un único instrumento de financiación y programación para la política rural que se denominará Fondo Europeo Agrario de Desarrollo Rural (FEADE). Con ello se solventarán los problemas anteriores de qué organismo debe financiar las actuaciones que se desarrollen.

- La Iniciativa Leader pasa a integrarse en la política rural con el objeto de ajustar los programas de desarrollo agrario a las necesidades locales, siguiendo el enfoque ascendente (bottom-up) que tan buenos resultados ha dado en la ya larga experiencia Leader.

Los objetivos que persigue la nueva política rural según la propuesta de la Comisión, son prácticamente los mismos que ya se vienen aplicando en los últimos años si bien reordenados de manera distinta. Tales objetivos son los tres siguientes:

- Mejora de la competitividad de la actividad agraria. Para conseguir la misma se mejorarán las infraestructuras agrarias, se apoyarán la instalación de jóvenes agricultores, se primaran a los agricultores que participen en los programas de calidad de los alimentos, etc.

- Medio ambiente y gestión del suelo. En este objetivo encajan las ayudas a la agricultura de montaña, Natura 2000 (fauna y hábitat), medidas agroambientales, ayudas a favor de los animales, etc. 
- Mejora de la calidad de vida y diversificación de actividades. Los programas más importantes que se prevé impulsar son los relacionados con la diversificación de las actividades no agrarias, promoción del turismo, ayudas para la creación de microempresas, renovación de núcleos rurales, etc.

\section{Espacio rural, protección agraria y actividad económica}

Teniendo presente que desde 1992 en adelante la PAC se está liberalizando con el objeto de que el comercio agrario se ajuste a las exigencias de la $\mathrm{OMC}$, ¿no es posible que la financiación de los programas de desarrollo rural -la producción agraria no comercializable- con recursos públicos sea una forma disfrazada de continuar protegiendo la PAC? Esto es lo que argumentan los competidores de la UE en los mercados agrarios internacionales -caso de Estados Unidos- y también los Estados que consideran a la PAC como una barrera inexpugnable para introducir sus productos en el mercado comunitario. Consideran que la política rural comunitaria consistente en subvencionar actividades no comercializables, no es más que un instrumento para encubrir el proteccionismo agrario de la UE. Sin embargo, esta argumentación carece de justificación al ser compatible aplicar recursos públicos al desarrollo rural con las reglas de buena conducta del comercio internacional que permite aquellas ayudas internas subsumibles en los supuestos previstos por la caja verde del Acuerdo de Agricultura en el marco de la OMC. Por lo tanto, tales ayudas públicas no deben ser consideradas como una subvención encubierta al sector agrario sino como una forma de mantener ocupado el espacio agrario y que lo sea por quienes mejor lo conocen: los agricultores. Ello significa que ha de subvencionarse su permanencia en el mismo para evitar que el modelo agrario comunitario llegue a los extremos del estadounidense donde virtualmente ya han desaparecido las explotaciones pequeñas y sobre todo las de tipo medio. Y la caja verde de la OMC debe contemplar estas situaciones. 
Pero, como hemos dicho, el medio rural comunitario ya no es sólo el espacio de la actividad agraria sino que es también, y cada vez en mayor medida, el asentamiento de otras actividades productivas. En la práctica no es fácil separar dichos ámbitos aun cuando las diferencias entre ellos comienzan ya a ser claras: el desarrollo rural es también un componente del desarrollo regional y no una simple extensión del agrario. Se ha pasado de un enfoque economicista que contemplaba primordialmente una política agraria de carácter sectorial, a otro horizontal en el que también se toma en consideración la dimensión espacial o regional." Es muy simplista considerar-sostiene el Comisario europeo de Agricultura y Desarrollo Rural - que los cambios que han afectado a las zonas rurales se deben exclusivamente a las consecuencias de la Política agrícola común (PAC), tampoco se deben olvidar los cambios que se han dado en las tecnologías, los estilos de vida, las expectativas de los consumidores o los modos de comunicación. Ello es especialmente verdad cuando se aprecia que se han producido tendencias similares en países que tienen políticas agrícolas distintas de la nuestra" ${ }^{29}$. La PAC no puede resolver por sí sola cuestiones tan importantes como, a modo de ejemplo, las del empleo o la conservación del medio ambiente, que han de ser abordadas de manera mas directa a través políticas apropiadas para acompañar los cambios que tienen lugar en las zonas rurales.

Aun cuando es cierto que la mayor parte de la política rural procede de la agraria, existe un componente regional que, inevitablemente, la hace cada vez más autónoma de aquella ${ }^{30}$. Si bien el espacio físico en décadas pasadas fue ocupado casi exclusivamente por la actividad agraria, los

${ }^{29}$ Fischler, F. "El Modelo rural europeo". LEADER Magazine no.25, Invierno 2000/ 2001

${ }^{30}$ En el sector agrario comunitario comienza a diferenciarse entre agricultura comercial y territorial. La primera corresponde a las explotaciones viables económicamente y se asocia, por lo común, a explotaciones de gran dimensión modernizadas y convenientemente gestionada que producen para el mercado (las que tienen un margen bruto anual de 18.000 o más UDEs -Unidad de Dimensión Económica-). La segunda, la forman pequeñas y medianas explotaciones de tipo familiar que carecen de viabilidad económica y cuya principal misión, en opinión de Regidor, es la preservación del paisaje y de los recursos naturales y que para sobrevivir tiene que estar fuertemente subvencionada. De las 1.023 mil explotaciones familiares existentes en España en 1997, sólo 117 mil eran viables económicamente y 916 mil no lo eran; si a esas 117 mil les sumamos otras 38 mil explotaciones viables de carácter no familiar, tenemos completo el panorama de la explotación agraria española. Véase Regidor, J. R. op. c. págs. 97 a 112. 
avances tecnológicos han incrementado en tal medida la productividad agraria que ha reducido el factor trabajo - y en también el factor tierra- a cotas realmente bajas. El proceso migratorio del ámbito rural al urbano, provocado en buena medida por los avances tecnológicos, se ha detenido ya en la mayoría de los Estados miembros de la UE-15 (aunque será muy importante en los próximos años en los nuevos Estados miembros ). Es más, desde hace una década estamos asistiendo -en concreto en el caso de España- a un cierto incremento de la población en el medio rural, sin perjuicio que en el ámbito agrario se continúa destruyendo empleo, lo que evidencia que las nuevas ocupaciones generadas en estas áreas ya no son de origen agrario. Si se acepta este razonamiento, lo que parece correcto a la luz de los estudios estadísticos y de un conocimiento directo de la realidad, el medio rural no puede ya ser considerado como una mera extensión de la actividad agraria, sino también el habitat de otras ocupaciones como las relativas al sector servicios. Como consecuencia del proceso de modernización de la agricultura, se ha producido una fuerte reducción de la población ocupada en la agricultura y una compleja articulación de la población y de la propia sociedad rural que afecta a la cualificación, flexibilidad, estrategias laborales y sistemas de organización social: "La terciarización de actividades agrarias, la pluriactividad, la agricultura a tiempo parcial, juntamente con la multifuncionalidad de la sociedad rural, conforman un nuevo escenario de las relaciones laborales y sociales en el medio rural y en el sector agrario" 31 .

Si se relaciona el tamaño de la población de los municipios españoles con la población económicamente activa, se aprecia que en aquellos que no superan los 1.000 habitantes, más de un tercio de su población activa se inscribe en la actividad agraria, casi una quinta parte en la industrial y otro tanto en los servicios, distribuyéndose el resto casi en partes iguales entre construcción y comercio. A medida que el municipio va incrementando tamaño de población, se aprecia un descenso creciente de la actividad agraria -sobre todo a partir de los 20.000 habitantes- a la

31 Ministerio de Agricultura, Pesca y Alimentación (MAPA)."Hechos y cifras...” op. c. pág. 29 
vez que se produce un incremento muy pronunciado en el de los servicios (que es paralelo al tamaño de la población) ${ }^{32}$.

Las nuevas tecnologías de la información permiten ya en numerosos casos el ejercicio profesional en el medio rural a través del teletrabajo. En los países desarrollados ya no es necesario residir en grandes ciudades para tener acceso a las fuentes de información y ni siquiera a las de ocio, pues dicho acceso hoy es posible desde cualquier lugar del territorio. Si a ello añadimos la considerable mejora y generalización gratuita de la educación y la sanidad y la posibilidad de contar con unas infraestructuras de transportes que permiten traslados rápidos a cualquier punto geográfico, es comprensible que muchos profesionales se establezcan en el medio rural, beneficiándose de un poder de adquisición mayor y de unas condiciones medioambientales más sanas.

Una de las características importantes del empleo en el medio rural es la del autoempleo. Esto no quiere decir que no existan empresas medianas e incluso grandes en el mismo, pero son más bien la excepción que la regla. La pequeña empresa e incluso la microempresa familiar que proporciona empleo al cabeza de familia y ayudas familiares -lo que técnicamente se conoce como autoempleo, es más bien la regla. El autoempleo se incrementa a medida que la población se va ruralizando. Puede establecer un corte diferencial importante entre los municipios españoles de más de 100 mil habitantes y los que no alcanzan dicha cifra $^{33}$. Así en las áreas metropolitanas, la proporción de autoempleados (autónomos, autoempleados en cooperativas y ayudas familiares) sobre el total empleo no alcanza la mitad del que existe en los municipios de menos de 20.000 habitantes (12,2\% y $29,9 \%$, respectivamente).

\footnotetext{
2 La información procede de Regidor, J. R. “Agricultura del medio rural en España....” op.c,. pág. 56.

33 En cambio, no se aprecian diferencias significativas entre los municipios cuya población se sitúa entre 100 mil y un millón de habitantes y el de las áreas metropolitanas (más de un millón de habitantes). Esto obedece a que la especialización productiva, en ambos supuestos, es bastante similar; en cambio, las diferencias ya son substanciales entre los anteriormente indicados y los que tienen entre 20 y 100 mil habitantes y, sobre todo, con los que no alcanzan los 20.000
} 
Pero que exista cada vez más autonomía del medio rural respecto del agrario, no significa que uno viva a espaldas del otro, más bien se trata de ámbitos interconectados puesto que todas las actividades que se desarrollan en el ámbito rural se interaccionan para asegurar su viabilidad económica y social. Como apunta Hervieu, las zonas rurales y las agrarias son dos mundos interdependientes: el desarrollo rural no puede basarse exclusivamente en el agrario, pero tampoco puede hacerse a espaldas de él. La propia idea de desarrollo rural ha surgido de la toma de conciencia de que el crecimiento de la productividad agraria obliga a buscar nuevas fuentes de empleo en el mundo rural para frenar el éxodo. "Se puede decir que la problemática del desarrollo rural ha derivado del éxito del desarrollo del modelo productivista en la agricultura.

La paradoja a la que nos enfrentamos es la siguiente: al mismo tiempo que Europa se ha convertido en una gran potencia agrícola y agroindustrial, ha dejado de ser una civilización agraria y para parte de sus territorios la agricultura ya sólo es una opción." 34 .

\section{Conclusiones}

1. En la medida en que la productividad agraria se ha ido incrementando, se han ido liberalizando importantes recursos tanto de suelo como de mano de obra. El agrario es el único de los sectores productivos que desde los años cincuenta viene destruyendo empleo de manera permanente en todos los países comunitarios (al menos en la UE de los quince). Por ello, una parte del colectivo social que con anterioridad se dedicaba a las faenas agrarias, ha ido quedando disponible para emplearse en otras actividades localizadas en su mayoría en la económica urbana, lo cual ha originado trasvases masivos de población del entorno ruralagrario al urbano. Desde que este último ha dejado de proporcionar puestos de trabajo suficientes para acoger a los excedentes agrarios y el entorno rural se ha modernizado en infraestructuras, es cuando ha comenzado a

${ }^{34}$ Hervieu, B. "Agricultura y desarrollo rural: la convergencia necesaria”. LEADER Magazine $\mathrm{n}^{\mathrm{o}} 15$, julio/ agosto 1997 
emerger con cierta luz propia el desarrollo rural. Nuevas tecnologías distintas de las agrarias- son las que están posibilitando que este espacio, difuso en sus límites, origine nuevas actividades productivas y requiera una atención creciente de los centros políticos de toma de decisiones.

2. El modelo rural comunitario, que es producto de la PAC y de la política de cohesión económica y social, no está aun lo suficientemente perfilado ni en su ámbito de actuación ni y en sus fuentes de financiación. Con relación al ámbito de actuación, en la política rural convergen programas tanto agrarios como regionales, diferenciando entre estos últimos entre regiones de Objetivos 1 y 2 a los que hay que sumar las Iniciativas LEADER y PRODER. En cuanto a las fuentes de financiación de la política rural, también cabe señalar un conjunto disperso de fondos aun cuando en su práctica totalidad corresponda a alguna de las dos secciones del FEOGA. Según la propuesta de la Comisión, previsiblemente esta cuestión se clarificará para el periodo 2007-13, según hemos visto anteriormente.

3. En el pasado todo el espacio rural en sus dimensiones territorial, económica, social y tecnológica, estaba ocupado por la actividad agraria. Hoy la actividad agraria, sin dejar de ser todavía la más importante de las realizadas en el medio rural, es una más entre ellas. A pesar de los contornos difusos que aun presenta la política rural comunitaria, si dicho modelo tiene algo de original, dicha originalidad reside en contemplar el medio rural como el entorno en el que puede darse la agricultura pero también otras actividades productivas. Es una concepción global del desarrollo rural que se preocupa por poner en tensión los recursos locales, en particular los humanos, y que pretende integrar de manera armónica y respetuosa con el desarrollo sostenible las dimensiones físicas, económicas, sociales, culturales y tecnológicas de los entornos rurales para potenciar su desarrollo endógeno. 
REVISTA DE ECONOMIA E AGRONEGÓCIO, VOL.3, No 1 